\title{
Process Mining for Advanced Service Analytics - From Process Efficiency to Customer Encounter and Experience
}

\author{
Sandra Zilker \\ FAU Erlangen-Nürnberg \\ sandra.zilker@fau.de
}

\author{
Emanuel Marx \\ FAU Erlangen-Nürnberg \\ emanuel.marx@fau.de
}

\author{
Matthias Stierle (D) \\ FAU Erlangen-Nürnberg \\ matthias.stierle@fau.de
}

\author{
Martin Matzner \\ FAU Erlangen-Nürnberg \\ martin.matzner@fau.de
}

\begin{abstract}
With the ongoing trend of servitization nurtured through digital technologies, the analysis of services as a starting point for improvement is gaining more and more importance. Service analytics has been defined as a concept to analyze the data generated during service execution to create value for providers and customers. To create more useful insights from the data, there is a continuous need for more advanced solutions for service analytics. One promising technology is process mining which has its origins in business process management. Our work provides insights into how process mining is currently used to analyze service processes and how it could be used along the service process. We find that process mining is increasingly applied for the analysis of the providers' internal operations, but more emphasis should be put on analyzing the customer interaction and experience.
\end{abstract}

\section{Introduction}

Companies are increasingly shifting their traditional product sales businesses towards bundles of goods, services, support, and knowledge [1] to increase productivity and remain internationally competitive $\sqrt{2}$. 3. 4]. While already in 1988 the term "servitization" was coined by Vandermerwe and Rada to describe this shift [5], servitization has gained traction lately in research and practice with the increase of digital technologies [6, 7].

Compared to products, services are more fuzzy, complex, and risky [8, 9], leaving servitization as a black box for companies [10, 11]. Therefore, to better understand and subsequently improve services, the analysis of services has received major attention in recent years. Furthermore, as services increasingly have digital touchpoints (e.g., through a web interface) or are even digital themselves (e.g., music streaming such as Spotify), more and more data are available for analysis that describe the service process, customer interaction, or customer behavior. Thus, the concept of service analytics has emerged as "the process of capturing, processing, and analyzing the data generated from the execution of a service system to improve, extend, and personalize a service to create value for both providers and customers" [12, p. 1]. Researchers see service analytics as a crucial capability for service providers to succeed, especially in digital marketplaces [13]. In particular, a focus on the service delivery process, hereafter referred to as the service process, is important, among others, to examine the roles and responsibilities of the stakeholders, maximize the value of the service to the customer, and enhance resource utilization [14].

To better structure the field of service analytics, Fromm et al. [15] propose the typology illustrated in Figure 1. They distinguish between basic (simple querying of structured data) and advanced analytics solutions (e.g., advanced methods from statistics or machine learning). Further, they propose three different perspectives of the analysis based on the type of data that is used. First, provider data allows the analysis of the internal operations. Second, encounter data describes the interaction between the provider and the customer. Third, customer data represents properties of the customer and service usage patterns that define the customer's experience of a service.

As concepts such as reporting or business intelligence have been around for a long time, organizations are firm in executing basic analytics on all data types. However, to persist in highly competitive marketplaces, companies need to generate more valuable insights from their data to improve their services [15]. Therefore, they seek advanced analytics solutions that provide new ways of analyzing data.

One technology for analyzing (process) data is process mining which has proven its value in many different domains. Process mining provides techniques and methods to discover process execution paths from process data, to check whether they complied with defined execution paths, and also to enhance the discovered execution paths by other perspectives such as 


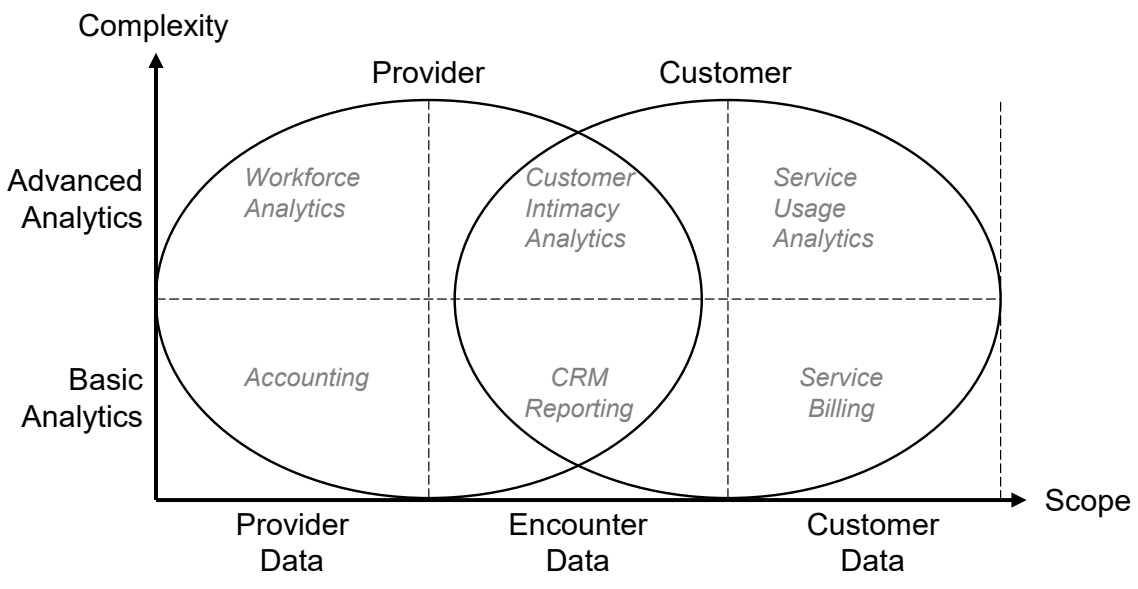

Figure 1. Typology by Fromm et al. [15] with exemplary applications.

throughput times [16]. To this date, several works apply process mining to service processes (e.g., [17, 18, 19]). However, most of these articles take a business process perspective - which is the home turf of process mining given its origins in business process management and do not refer to insights and approaches of service science, especially those of value co-creation. The participation of the customer in service delivery [20] makes service processes more difficult to measure. The quality is reflected in customer criteria, such as customer satisfaction [21]. Still, it is unclear if the usage of process mining is restricted to the provider data to analyze the efficiency of the service provision. In order to be a valuable solution for advanced service analytics, we would expect that especially the service encounter and the customer itself are at the center of the analysis. A holistic approach that identifies the characteristics and challenges of service processes and potential application areas (i.e., provider, encounter, and customer) for the capabilities of the process mining technology would be of interest to both process miners that intend to enter the service domain and service analysts that seek to exploit process mining as an additional tool.

Therefore, we define our research question as follows:

How could the different types of process mining (i.e., discovery, conformance checking, and process enhancement) be used to analyze the different perspectives of service processes (i.e., provider, encounter, and customer)?

To answer this question, we first draw on existing literature to identify how process mining was or is currently used for the analysis of service processes. Second, we design a framework that presents various further dimensions for the analysis of service processes with process mining.
Therefore, our paper is structured as follows: Section 2 provides background information on service systems and service processes and Process Mining (PM) and shows related work. Section 3 gives an overview of different analysis dimensions for the application of PM for service analysis. Lastly, in Section 4 we discuss implications and limitations and provide an outlook.

\section{Background}

\subsection{Process Mining}

PM bridges the gap between data mining and business process modeling and analysis [16]. The overall goal is to "discover, monitor, and improve real processes [...]" [16].

Therefore, PM extracts information from event logs. Software systems record events sequentially so that these events refer to activities and are related to a specific case. Therefore, event logs contain a unique identifier for each case, the activities executed, and a timestamp for each activity. Besides this control-flow information, further information is stored by the software system and thus can be part of the event $\log$, such as resources (i.e., the person executing a certain activity).

PM can be differentiated based on the type and consequently the input and output. The most basic type is Process Discovery, which generates a model - typically a process model - from an event log. It enables users to gain insights into the process for process analysis and reveals patterns that may not have been observed before. Further, Conformance Checking techniques use a given model in addition to the event $\log$ to determine whether and how process behavior, extracted from the event log, differs from the 
model. These models can be, e.g., a process model, an organizational model, or even policies. Therefore, these methods compare the "as-is" model with the "to-be" model, which might uncover errors in both the actual process executions and the planned process. Lastly, Enhancement techniques use an event log and a model as input, retrieve (additional) information from the event $\log$, and add this information to the model. The output is then an improved model. Some definitions of enhancement also include extending existing models [16] besides creating improved models which is however not considered in this work.

\subsection{Service Systems and Service Processes}

To describe the characteristics of services and derive possible applications of PM on service processes, we refer to the understanding of services as proposed by the research discipline service science. While service science has originated in service marketing and service management [22], Information Systems researchers increasingly address this field as well [23]. One reason is the thematic proximity, as both service science and IS investigate phenomena from a socio-technical perspective, where comparable importance is ascribed to both social and technical components [24].

One guiding concept is that of service systems which alters the perception of service provision and value creation [25]. Previously, service provision was often described as a linear, dyadic interaction in which a supplier provides something to a customer viewed as a passive recipient [26]. Recent research rather takes a network or system perspective [27] in which value is co-created by multiple actors (i.e., individuals, collectives, or even smart technologies) that contribute to an overarching solution [20]. In these systems, the actors share their resources and access the resources provided by others [28, 29, 26]. Thus, Maglio et al. define a service system as a "value-cocreation configuration of resources, including people, organizations, shared information (language, laws, measures, methods), and technology, all connected internally and externally to other service systems by value propositions" [25, p. 399].

An established separation of services to physical goods is attributed to the service process [30], which consists of a set of connected activities necessary to provide a service and describe "procedure[s], mechanism[s], and operation flow[s]" [21, p. 21]. Unlike physical goods, services are not produced in advance and sold as a finished good but "emerge" during the service process, whereby the customer is involved [31, 32]. This customer orientation bears challenges for service process design and management that differ from regular business processes, such as the integration of the customer as an external factor into the service process, who performs activities, and for this needs to possess or have access to specific resources and skills [33]. Additionally, the achievement of quality objectives sought by the customers is in focus [21]. As a result, service process modeling tools such as the service blueprint (e.g., [30, 33, 34, 35. 14]) differentiate between customer and provider activities to allow for the isolation of customer-related tasks [36] and also consider the customers' touchpoints with the service [14]. Furthermore, front- and backstage activities on the provider's side are often distinguished [36, 37], as front-stage activities are visible to the customer and influence experienced value and quality.

\subsection{Related Work}

To provide an overview of the current state of the application of PM for service analytics, we conducted a semi-systematic literature review using the databases Scopus and IEEE Xplore [38]. For the search, we focused on the terms Process Mining and Service Analytics. Additionally, we screened case studies included in [39] and added papers from our existing knowledge base. Next, we scanned both title and abstract, resulting in 23 relevant works. So far, different papers have investigated the use of PM for service analytics, as summarized in Table 11. These focus mainly on provider and encounter data. However, little research has been conducted regarding the use of PM for customer data. Further, most studies investigate the application of process discovery to discover the process model from event log data and to calculate certain key performance indicators.

Dustdar et al. [40] use process discovery to mine interaction between web services in the context of film crew management. Dustdar and Gombotz [41] focus on the discovery of web service workflows. Zhou et al. [21] investigate a telephone repair process with process discovery. They aim to demonstrate how service actors co-create value during the execution of a service process, which helps them to achieve their value goals. Werner [42] applies process discovery to the financial domain to discover a process model from accounting data.

Lillig [43] aims at analyzing their core processes. The overall goal was to investigate where to reduce lead time, how to decrease complexity and thus increase the processes' efficiency.

Boenner [44] focuses on how PM can support 


\begin{tabular}{|c|c|c|c|c|c|c|}
\hline \multirow{2}{*}{ Source } & \multicolumn{2}{|c|}{ Data Scope } & \multicolumn{3}{|c|}{ Type of PM } & \multirow{2}{*}{ Goal } \\
\hline & $\mathrm{P} \quad \mathrm{E}$ & $\mathrm{C}$ & $\mathrm{D}$ & $\mathrm{CC}$ & PE & \\
\hline$[40]$ & • & & - & & & Discover interactions of web services \\
\hline [41] & • & & • & & & Discover process model \\
\hline [21] & • & & • & & & Accelerate the process of servitization \\
\hline$[\overline{42}]$ & $\bullet$ & & • & & & Discover process model \\
\hline [43] & • & & - & & & Analyze lead time and where to reduce complexity \\
\hline [44] & • & & - & • & & Analyze deviations, identify contact person \\
\hline [17] & • & & • & $\bullet$ & • & Analyze correlation of instances of different service, waiting time \\
\hline$[45$ & - & & - & & & Discover process model (+ Correlation analysis) \\
\hline [36] & - & & - & & & Analyze occurrence and duration of waiting time \\
\hline [46] & - & & • & & & Discover process model; Analyze speed to answer request \\
\hline [47] & - & & • & & & Improve process coordination, root cause analysis \\
\hline [48] & - & & • & & & Improve customer satisfaction \\
\hline$[\overline{49}]$ & $\bullet$ & & • & & & Analyze customer journey for customer support \\
\hline [50] & $\bullet$ & & • & & & Discover and analyze process model \\
\hline$[\overline{51}]$ & $\bullet$ & & & • & & Choreography conformance checking \\
\hline$[\overline{19}]$ & $\bullet$ & & • & • & & Analyze number of correctly replayed tickets \\
\hline [18] & - & & • & - & - & Cross-organizational PM \\
\hline$[\overline{52}]$ & • & & • & • & • & Positive outcomes for clients, customer work, efficiency \\
\hline [53] & • & & • & • & • & Analyze customer interactions, throughput time, automation, costs \\
\hline$[54$ & & • & - & & & Discover models of customer behavior from sensor data \\
\hline [55] & & • & • & & & $\begin{array}{l}\text { Discover models of user behavior, compare variants, improve Key } \\
\text { performance indicators }\end{array}$ \\
\hline$[\overline{56}$ & & • & • & & & Compare different PM algorithms for process discovery \\
\hline [57] & & - & • & & & Create customer journey map model \\
\hline
\end{tabular}

P: Provider Data, E: Encounter Data, C: Customer Data; D: Discovery, CC: Conformance Checking, PE: Process Enhancement

Table 1. Overview on existing literature of $P M$ in service analytics.

digital transformation in internal auditing. Besides process discovery, they also conduct conformance checking and analyze process deviations. Lastly, van der Aalst [17] demonstrates how process discovery, conformance checking, and enhancement can be used in the service context focusing on provider data.

Besides provider data, multiple studies have investigated PM for service analytics based on encounter data. Rahmadi et al. [45] discover process models in the context of Human Resources, more specifically, the recruiter's process to send out interview invitations to prospective candidates. Leyer and Moormann [36] combine PM with statistical methods for a loan application process in a bank for small and medium-sized enterprises. They first discover the process model from an event log, and then they analyze the occurrence and duration of waiting time for the customer. Lamine et al. [46] focus on the emergency call service. They first discover the process model, based on that, they create the to-be model, and lastly, they analyze the speed to answer a call. Edgington et al. [47] develop and evaluate a model for an outsourcing provider's organization in the case of helpdesk services. Gras et al. [48] analyze the service delivery process of a large Dutch telecommunication service provider with process discovery. They focus on different metrics, e.g., number of activities or sequence of activities, aiming to improve customer satisfaction. Rowlson [49] aims at providing better visibility of their business processes by analyzing the variation in customer support, which resulted in increased efficiency. Mahendrawathi et al. [50] discover a process model from real-life event data, analyze the different variants and gather valuable insights for process improvement. Van der Aalst et al. [51] apply conformance checking for logistics services, e.g., shipment tracking. Vázquez-Barreiros et al. [19] use process discovery and conformance checking for IT service management and investigate metrics like the number of correctly replayed tickets. Van der Aalst [18] applies the three types of PM on a cross-organizational level. The author uses the cloud infrastructure for municipalities to analyze different services, i.e., handling various types of permits, taxes, certificates, and licenses. Balint et al. [52] focus on using PM for 
service integrity in a healthcare process. They aim at achieving three different goals. First, to increase the positive outcomes for the patients by handling claims faster. Second, to reduce the administrative tasks. Lastly, to reduce the operational costs. Henriques [53] uses process discovery, conformance checking, and enhancement in a Portuguese electric utility company to analyze customer interactions, throughput time, automation rate, and costs. Ultimately, the author aims to reduce the analytical speed, increase the ability to deal with business changes, get a clear understanding of the processes, and anticipate issues with operational alarms.

In the current research, PM based on customer data focuses on process discovery. Van Eck et al. [54] aim at discovering user behavior using sensor data gathered from a smart product. In their use case, they investigated the feeding process of a baby with a sensor-equipped bottle. The insights gathered from process discovery helped product designers to improve their products.

Terragni and Hassani [55] analyze the customer journey with process mining to discover the process which describes the user behavior, compare process variants, gain meaningful insights and consequently improve certain KPIs. Poggi et al. [56] compare different PM algorithms for business model extractions based on real-life web data. Bernard and Andritsos [57] analyze the customer journey and propose a customer journey map model enabling a better understanding of the customers' behavior.

\section{Process Mining for Service Analytics}

With a focus on service analytics in general, Fromm et al. [15] establish a framework for distinguishing diverse service analytics approaches and their addressed purposes (see Figure 1). In this framework, the authors distinguish between basic and advanced analytics on the one hand and the dimensions customer, encounter, and provider on the other. Furthermore, while they define basic analytics as standard ad hoc reporting, or queries, advanced analytics contain different methods with a descriptive, predictive, and prescriptive perspective [15].

Concerning our research questions, we consider PM to be part of advanced analytics, focusing on descriptive analyses. Furthermore, we argue that PM should be applied to all three data dimensions. Therefore, our framework (see Table 2) summarizes different dimensions, which could be analyzed with PM regarding service analytics. The table is divided by data type as suggested by Fromm et al. [15] and shows the corresponding type of PM.

\subsection{Provider Data}

In general, provider data allows the analysis of the efficiency of operation. Perceived service complexity, as conceptualized by Kostopoulos et al. [58], can be measured with provider data. More specifically, perceived complexity can be task-related and can be measured by process variants (i.e., which and how many different variations of a process exist), service tasks (i.e., which and how many tasks or activities need to be executed by a service employee), and duration of tasks (i.e., how long an employee takes to execute a certain task or activity). Besides process discovery, conformance checking [59] can be executed to determine if service employees adhere to the defined process model. Two different types of analysis can be executed to achieve process enhancement. First, social network analysis [60] can demonstrate how different departments or even service employees work together. This is not specifically on an individual level but on a role level. Based on this, issues, e.g., bottleneck, can be detected and consecutively be solved. Second, on a resource level, a resource analysis can investigate resource capacity and utilization. Thus, bottlenecks can be located and, in the next step, eliminated. This can be from a Human Resource perspective regarding employee positioning and workload allocation [61], but also in regards to, e.g., devices.

\subsection{Encounter Data}

In regards to encounter data, the focus of analysis is on the quality of interaction. From a provider perspective, perceived complexity, as described above, can be analyzed [58]. The same dimensions are relevant for a customer journey analysis from a customer perspective [62] and therefore are not added redundantly. The perceived service complexity can be extended beyond the task-related to customer-derived aspects. This is when a customer participates in the delivery of a service process. The customer-derived view focuses on the number of customers, the intensity of contacts (i.e., the duration of interactions with a customer), and the variation in customer needs (i.e., how many different types of interactions, e.g., requests, occur) [58]. Where perceived complexity concerns the perspective of service providers in general, and service employees in specific, customer contact focuses on the perspective of the customer. Customer contact includes communication time, spatial proximity, and information richness [63]. Communication time determines the total interaction time of a service employee and a customer [64]. Spatial proximity, in general, focuses 


\begin{tabular}{|c|c|c|c|c|}
\hline \multirow{2}{*}{\multicolumn{2}{|c|}{ Analysis Dimensions }} & \multicolumn{3}{|c|}{ Type of PM } \\
\hline & & & $\mathrm{CC}$ & $\mathrm{PE}$ \\
\hline \multirow{8}{*}{ 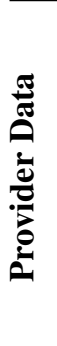 } & Efficiency of operation & & & \\
\hline & Perceived service complexity & • & & \\
\hline & Process variants & • & & \\
\hline & Service activities & - & & \\
\hline & Duration of activities & • & & \\
\hline & Service employees adhere to defined process model & & • & \\
\hline & How departments/ service employees work together (Social Network Analysis) & & & • \\
\hline & Resource capacity and utilization (Resource Analysis) & & & • \\
\hline \multirow{19}{*}{ 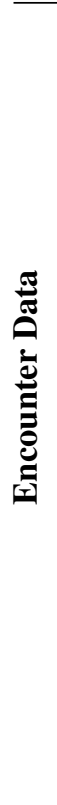 } & Quality of interaction & & & \\
\hline & Perceived service complexity and customer journey & - & & \\
\hline & Process variants & • & & \\
\hline & (Service) activities & • & & \\
\hline & Duration of activities & • & & \\
\hline & Number of customers & • & & \\
\hline & Intensity of contacts & • & & \\
\hline & Variation in customer needs & - & & \\
\hline & Communication time & • & & \\
\hline & Total time spent to interact & • & & \\
\hline & Spatial proximity & $\bullet$ & & \\
\hline & Distance between customer and service employees during service process & $\bullet$ & & \\
\hline & Waiting time & • & & \\
\hline & Number of service employees available & • & & \\
\hline & Information richness & • & & \\
\hline & Amount and frequency of communication & • & & \\
\hline & Number of communication channels & • & & \\
\hline & Interaction as expected or determined & & • & \\
\hline & How service employees and customers interact (Social Network Analysis) & & & • \\
\hline \multirow{11}{*}{ 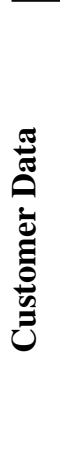 } & Customer experience & & & \\
\hline & Customer journey & - & & \\
\hline & Executed activities & • & & \\
\hline & Duration of activities & • & & \\
\hline & Service usage patterns & • & & \\
\hline & Changes in service usage patterns & • & & \\
\hline & Customer Retention & • & & \\
\hline & Frequency of service usage & • & & \\
\hline & Recency of service usage & • & & \\
\hline & Variation in customer needs & - & & \\
\hline & Customer activities as expected or determined & & • & \\
\hline
\end{tabular}

D: Discovery, CC: Conformance Checking, PE: Process Enhancement

Table 2. Framework for the application of PM for advanced service analytics.

more on the customer perspective and encourages feelings of personal involvement, and enhances the customer's perceived trustworthiness of the service employee [65]. In regards to PM, one can measure the distance between the service employee and a customer during the service process, e.g., was the communication in person, via phone, or via E-Mail. Further, the waiting time for the customer and, closely related, the number of service employees available can be evaluated with process discovery [63]. The waiting time can also be analyzed from a service employee's perspective, i.e., how long the reaction time of a customer is. Lastly, information richness [66] can be measured by the amount and frequency of communication between the customer and the service employee and the number of communication channels. 
Beyond process discovery, conformance checking can analyze whether the interaction between service employees and customers is as expected or determined [59.51]. For this, multiple of the dimension explained above can be used. For example, if customer waiting times are supposed to be no longer than a set amount of time, the percentage of deviant cases can be determined. Lastly, social network analysis [60] can demonstrate how service employees and customers interact. Then, issues, e.g., bottlenecks, can be detected and consecutively be solve resulting in process enhancement.

\subsection{Customer Data}

To understand customer experience, the customer journey can be analyzed using customer data [67, 68]. With process discovery, the executed activities, the duration spent per activity, and the process variants can be analyzed to better understand customer behavior [62. 69]. Further, analyzing service usage patterns aims at discovering how customers use a specific service [70]. Based on that, changes in usage patterns over time can be detected. Thus, service providers will be able to react to these changes by possibly adapting their service. Depending on the underlying use case, customer retention is worth analyzing with PM [71]. Indicators are frequency and recency of service usage [72], i.e., the number of times a customer is recurring and the time to the last usage of the service. Closely related is the analysis of variation in customer needs [58] represented by, e.g., the number of different request types. In regards to conformance checking [59], deviations between expected and executed activities can be analyzed, e.g., with respect to the order and the duration of activities.

\section{Discussion}

\subsection{Implications}

This research focuses on the application of PM for service analytics. In general, analyzing service processes with PM provides several advantages, e.g., in regards to customer journey analysis, such as strengthening customer relationships [73] and improving service quality [62]. In this paper, we first provided an overview of PM and service processes in general and showed how PM is currently used to analyze service processes based on existing literature. We raise awareness that PM can be an additional means in the rich service analytics toolbox.

Second, we derived possible analysis dimensions based on the different data types. In this cause, we adopt the service analytics framework by Fromm et al. [15] and suggest potential questions for PM applications depending on the three framework dimensions: provider, encounter, and customer. Our overview shows that while PM has been predominantly applied for provider or encounter data, customer data falls short. One reason for this could be the often more convenient access to these types of data, e.g., through Customer Relationship Management Systems. Customer data, however, can be hard to track and collect and, therefore, be less analyzed. Nevertheless, customer integration and co-creation are essential service system concepts that need further consideration in PM literature.

Additionally, encounter data includes activities executed from both the provider and the customer side. Therefore, some analyses might be biased if not conducted selectively. For example, in regards to efficiency, not all executed activities are relevant for analysis as the provider mostly has no influence on how fast the customer executes a certain activity.

Finally, some dimensions might be perceived as either positive or negative depending on the nature of the process. For example, high customer retention is positive for sales-related processes, meaning a customer was satisfied with their past experience and therefore returned. However, concerning claim management, returning customers could identify dissatisfied customers or even issues with the products sold. Therefore, further analyses should be performed consecutively, e.g., root-cause analysis.

\subsection{Limitations}

Similar to other research, ours is not free of limitations. First, in our work we differentiate between three different data types based on the typology introduced by Fromm et al. [15]. Other works, e.g., the four types on user's and provider's activity level proposed by Wünderlich et al. [74], could be used to frame the dimensions. Second, we propose a framework that suggests further aspects for analysis of service processes - in particular, for analyzing customer encounters and experience. However, the utility of the framework has not been evaluated yet, for example, by applying it to a real-world use case.

\subsection{Outlook}

In future research, we plan to demonstrate the framework by analyzing the suggested dimensions from a real-life event log. This would provide valuable insights regarding the framework's potential but also it would help to assess if event logs currently hold enough information to analyze customer encounters and 
experience.

Further, according to Dumas [75], PM will experience a shift from PM 1.0 to PM 2.0. While PM 1.0 refers to descriptive analyses, i.e., automated process discovery and analysis, PM 2.0 aims at diagnostic, predictive, and prescriptive analysis, i.e., predictive process monitoring and automated process improvement. Therefore, the need for analysis techniques for service processes will also evolve, as Fromm et al. [15] include predictive and prescriptive perspectives for advanced service analytics in their typology.

We think that process mining has great potential to support service providers in their quest for better understanding their customers. With service offerings evolving quickly, process mining provides advanced analytical capabilities to analyze service usage and to subsequently improve and adjust service systems when necessary. In the future, predictive and prescriptive techniques might also be applied for service analytics.

\section{Acknowledgements}

This project is funded by the German Federal Ministry of Education and Research (BMBF) within the framework programme Software Campus (www.softwarecampus.de) under the number 01IS17045.

\section{References}

[1] T. Paschou, M. Rapaccini, F. Adrodegari, and N. Saccani, "Digital Servitization in Manufacturing: A Systematic Literature Review and Research Agenda," Industrial Marketing Management, vol. 89, pp. 278-292, 2020.

[2] A. Tukker and U. Tischner, "Product-Services as a Research Field: Past, Present and Future. Reflections from a Decade of Research," Journal of Cleaner Production, vol. 14, no. 17, pp. 1552-1556, 2006.

[3] T. S. Baines, H. W. Lightfoot, S. A. R. Evans, A. Neely, R. Greenough, J. Peppard, R. Roy, E. Shehab, A. Braganza, and A. Tiwari, "State-of-the-Art in Product-Service Systems," Journal of Engineering Manufacture, vol. 221, no. 10, pp. 1543-1552, 2007.

[4] Y. Qi, Z. Mao, M. Zhang, and H. Guo, "Manufacturing Practices and Servitization: The Role of Mass Customization and Product Innovation Capabilities," International Journal of Production Economics, vol. 228, pp. 1-10, 2020.

[5] S. Vandermerwe and J. Rada, "Servitization of Business: Adding Value by Adding Services," European Management Journal, vol. 6, no. 4, pp. 314-324, 1988.

[6] A. G. Frank, G. H. Mendes, N. F. Ayala, and A. Ghezzi, "Servitization and Industry 4.0 Convergence in the Digital Transformation of Product Firms: A Business Model Innovation Perspective," Technological Forecasting and Social Change, vol. 141, no. 1, pp. 341-351, 2019.
[7] M. Kohtamäki, V. Parida, P. Oghazi, H. Gebauer, and T. Baines, "Digital Servitization Business Models in Ecosystems: A Theory of the Firm," Journal of Business Research, vol. 104, no. 1, pp. 380-392, 2019.

[8] E. J. Nijssen, B. Hillebrand, P. A. Vermeulen, and R. G. Kemp, "Exploring Product and Service Innovation Similarities and Differences," International Journal of Research in Marketing, vol. 23, no. 3, pp. 241-251, 2006.

[9] C. Schultz, D. Globocnik, A. Kock, and S. Salomo, "Application and Performance Impact of Stage-Gate Systems - The Role Services in the Firm's Business Focus," R\&D Management, vol. 49, no. 4, pp. 534-554, 2019.

[10] W. Coreynen, P. Matthyssens, R. de Rijck, and I. Dewit, "Internal Levers for Servitization: How Product-Oriented Manufacturers can Upscale Product-Service Systems," International Journal of Production Research, vol. 56, no. 6, pp. 2184-2198, 2018.

[11] M. M. Kamal, U. Sivarajah, A. Z. Bigdeli, F. Missi, and Y. Koliousis, "Servitization Implementation in the Manufacturing Organisations: Classification of Strategies, Definitions, Benefits and Challenges," International Journal of Information Management, vol. 55, no. 6, pp. 1-15, 2020.

[12] J. Cardoso, J. Hoxha, and H. Fromm, "Service Analytics," in Fundamentals of Service Systems, pp. 179-215, Springer, 2015.

[13] S. Akter, S. Motamarri, U. Hani, R. Shams, M. Fernando, M. Mohiuddin Babu, and K. Ning Shen, "Building Dynamic Service Analytics Capabilities for the Digital Marketplace," Journal of Business Research, vol. 118, pp. 177-188, 2020.

[14] D.-H. Ryu, C. Lim, and K.-J. Kim, "Development of a Service Blueprint for the Online-to-Offline Integration in Service," Journal of Retailing and Consumer Services, vol. 54, pp. 1-10, 2020.

[15] H. Fromm, F. Habryn, and G. Satzger, "Service Analytics: Leveraging Data Across Enterprise Boundaries for Competitive Advantage," in Globalization of Professional Services, pp. 139-149, Springer, 2012.

[16] W. van der Aalst, A. Adriansyah, A. K. A. De Medeiros, F. Arcieri, T. Baier, T. Blickle, J. C. Bose, P. Van Den Brand, R. Brandtjen, J. Buijs, et al., "Process Mining Manifesto," in Proceedings of the 7th International Workshop on Business Process Intelligence (BPI), pp. 169-194, 2011.

[17] W. van der Aalst, "Service Mining: Using Process Mining to Discover, Check, and Improve Service Behavior," IEEE Transactions on Services Computing, vol. 6, no. 4, pp. 525-535, 2013.

[18] W. van der Aalst, "Configurable Services in the Cloud: Supporting Variability While Enabling Cross-Organizational Process Mining," in Proceedings of the OTM Confederated International Conferences 'On the Move to Meaningful Internet Systems', 2010.

[19] B. Vázquez-Barreiros, D. Chapela, M. Mucientes, M. Lama, and D. Berea, "Process Mining in IT Service Management: A Case Study," in Proceedings of ATAED@Petri Nets/ACSD, pp. 16-30, 2016.

[20] B. Clarysse, M. Wright, J. Bruneel, and A. Mahajan, "Creating Value in Ecosystems: Crossing the Chasm Between Knowledge and Business Ecosystems," Research Policy, vol. 43, no. 7, pp. 1164-1176, 2014. 
[21] X. Zhou, G. Zacharewicz, D. Chen, and D. Chu, "A Method for Building Service Process Value Model Based on Process Mining," Applied Sciences, vol. 10, no. 20, pp. 1-25, 2020.

[22] L. L. Dodson, S. R. Sterling, and J. K. Bennett, "Considering Failure: Eight Years of ITID Research," in Proceedings of the 5th International Conference on Information and Communication Technologies and Development, pp. 19-34, 2012.

[23] D. Beverungen, "Mapping the Emerging Field of Service Science: Insights from a Citation Network and Cocitation Network Analysis," in Proceedings of the 31st International Conference on Information Systems, 2011.

[24] S. Sarker, S. Chatterjee, X. Xiao, and A. Elbanna, "The Sociotechnical Axis of Cohesion for the IS Discipline: Its Historical Legacy and its Continued Relevance," MIS Quarterly, vol. 43, no. 3, pp. 695-719, 2019.

[25] P. Maglio, S. L. Vargo, N. Caswell, and J. C. Spohrer, "The Service System is the Basic Abstraction of Service Science," Information Systems and e-Business Management, vol. 7, no. 4, pp. 395-406, 2009.

[26] R. F. Lusch and S. Nambisan, "Service Innovation: A Service-Dominant Logic Perspective," MIS Quarterly, vol. 39, no. 1, pp. 155-175, 2015.

[27] A. Frey, M. Trenz, and D. Veit, "A Service-Dominant Logic Perspective on the Roles of Technology in Service Innovation: Uncovering Four Archetypes in the Sharing Economy," Journal of Business Economics, vol. 89, no. 8-9, pp. 1149-1189, 2019.

[28] R. Badinelli, S. Barile, I. Ng, F. Polese, M. Saviano, and P. Di Nauta, "Viable Service Systems and Decision Making in Service Management," Journal of Service Management, vol. 23, no. 4, pp. 498-526, 2012.

[29] S. L. Vargo and R. F. Lusch, "Service-Dominant Logic: Continuing the Evolution," Journal of the Academy of Marketing Science, vol. 36, no. 1, pp. 1-10, 2008.

[30] M. J. Bitner, A. L. Ostrom, and F. N. Morgan, "Service Blueprinting: A Practical Technique for Service Innovation," California Management Review, vol. 50, no. 3, pp. 66-94, 2008.

[31] A. Mina, E. Bascavusoglu-Moreau, and A. Hughes, "Open Service Innovation and the Firm's Search for External Knowledge," Research Policy, vol. 43, no. 5, pp. 853-866, 2014.

[32] C. Engel and P. Ebel, "Data-Driven Service Innovation: A Systematic Literature Review and Development of Research Agenda," in Proceedings of the 27th European Conference on Information Systems (ECIS), 2019.

[33] S. Fließ and M. Kleinaltenkamp, "Blueprinting the Service Company," Journal of Business Research, vol. 57, no. 4, pp. 392-404, 2004

[34] G. Lynn Shostack, "How to Design a Service," European Journal of Marketing, vol. 16, no. 1, pp. 49-63, 1982.

[35] J. Kingman-Brundage, "The ABC's of Service System Blueprinting: Designing a Winning Service Strategy," in Proceedings of the 7th Annual Services Marketing Conference, 1989.

[36] M. Leyer and J. Moormann, "Combining Process Mining and Statistical Methods to Evaluate Customer Integration in Service Processes," Lecture Notes in Business Information Processing, vol. 99, no. 1, pp. 147-152, 2012.
[37] J. Becker, D. Beverungen, R. Knackstedt, M. Matzner, O. Muller, and J. Poppelbuss, "Bridging the Gap Between Manufacturing and Service Through IT-Based Boundary Objects," IEEE Transactions on Engineering Management, vol. 60, no. 3, pp. 468-482, 2013.

[38] H. Snyder, "Literature review as a research methodology: An overview and guidelines," Journal of Business Research, vol. 104, pp. 333-339, 2019.

[39] L. Reinkemeyer, Process Mining in Action: Principles, Use Cases and Outlook. Springer Nature, 2020.

[40] S. Dustdar, R. Gombotz, and K. Baina, "Web Services Interaction Mining," Data, vol. 55, no. 2, pp. 129-158, 2004.

[41] S. Dustdar and R. Gombotz, "Discovering Web Service Workflows Using Web Services Interaction Mining," International Journal of Business Process Integration and Management, vol. 1, no. 1, pp. 256-266, 2006.

[42] M. Werner, "Financial Process Mining - Accounting Data Structure Dependent Control Flow Inference," International Journal of Accounting Information Systems, vol. 25, pp. 57-80, 2017.

[43] G. Lillig, "Telekom: Process Mining in Shared Services," in Process Mining in Action (L. Reinkemeyer, ed.), pp. 59-63, Springer, 2020.

[44] A. Boenner, "Bayer: Process Mining Supports Digital Transformation in Internal Audit," in Process Mining in Action (L. Reinkemeyer, ed.), pp. 159-168, Springer, 2020.

[45] F. Rahmadi and G. A. P. Saptawati, "Identification Process Relationship of Process Model Discovery Based on Workflow-Net," in Proceedings of the International Conference on Data and Software Engineering (ICoDSE), 2018.

[46] E. Lamine, F. Fontanili, M. Di Mascolo, and H. Pingaud, "Improving the Management of an Emergency Call Service by Combining Process Mining and Discrete Event Simulation Approaches," in Risks and Resilience of Collaborative Networks (L. M. Camarinha-Matos, F. Bénaben, and W. Picard, eds.), pp. 535-546, Springer, 2015.

[47] T. M. Edgington, T. Raghu, and A. S. Vinze, "Using Process Mining to Identify Coordination Patterns in IT Service Management," Decision Support Systems, vol. 49, no. 2, pp. 175-186, 2010

[48] F. Gras, P. Ravesteijn, M. van Steenbergen, and R. Bijvank, "Business Customer Experience Alignment Framework: Improving Customer Satisfaction," in Proceedings of the 31st Bled eConference: Digital Transformation: Meeting the Challenges, 2018.

[49] M. Rowlson, "Uber: Process Mining to Optimize Customer Experience and Business Performance," in Process Mining in Action (L. Reinkemeyer, ed.), pp. 59-63, Springer, 2020.

[50] E. Mahendrawathi, H. M. Astuti, and A. Nastiti, "Analysis of customer fulfilment with process mining: A case study in a telecommunication company," Procedia Computer Science, vol. 72, pp. 588-596, 2015.

[51] W. Van Der Aalst, M. Dumas, C. Ouyang, A. Rozinat, and E. Verbeek, "Conformance Checking of Service Behavior," ACM Transactions on Internet Technology, vol. 8, no. 3, pp. 1-30, 2008.

[52] C. Balint, Z. Taylor, and E. James, "athenahealth: Process Mining for Service Integrity in Healthcare," in Process Mining in Action (L. Reinkemeyer, ed.), pp. 97-108, Springer, 2020. 
[53] R. Henriques, "EDP Comercial: Sales and Service Digitization," in Process Mining in Action (L. Reinkemeyer, ed.), pp. 109-118, Springer, 2020.

[54] M. L. van Eck, N. Sidorova, and W. van der Aalst, "Enabling Process Mining on Sensor Data from Smart Products," in Proceedings of the 10th International Conference on Research Challenges in Information Science, 2016.

[55] A. Terragni and M. Hassani, "Analyzing Customer Journey with Process Mining: From Discovery to Recommendations," in 2018 IEEE 6th International Conference on Future Internet of Things and Cloud, pp. 224-229, 2018.

[56] N. Poggi, V. Muthusamy, D. Carrera, and R. Khalaf, "Business Process Mining from E-Commerce Web Logs," in Business Process Management (F. Daniel, J. Wang, and B. Weber, eds.), (Berlin, Heidelberg), pp. 65-80, Springer Berlin Heidelberg, 2013.

[57] G. Bernard and P. Andritsos, "A Process Mining Based Model for Customer Journey Mapping," in Forum and Doctoral Consortium Papers Presented at the 29th International Conference on Advanced Information Systems Engineering, vol. 1848, pp. 49-56, CEUR Workshop Proceedings, 2017.

[58] I. Kostopoulos, A. Boukis, and G. Lodorfos, "Conceptualizing and Measuring Perceived Service Complexity," Journal of Marketing Theory and Practice, vol. 27, no. 1, pp. 38-54, 2019.

[59] A. Rozinat and W. van der Aalst, "Conformance Checking of Processes Based on Monitoring Real Behavior,' Information Systems, vol. 33, no. 1, pp. 64-95, 2008.

[60] J. Scott, "Social Network Analysis," Sociology, vol. 22, no. 1 , pp. 109-127, 1988.

[61] H. Eiselt and V. Marianov, "Employee Positioning and Workload Allocation," Computers \& Operations Research, vol. 35, no. 2, pp. 513-524, 2008.

[62] R. Halvorsrud, K. Kvale, and A. Følstad, "Improving Service Quality Through Customer Journey Analysis," Journal of Service Theory and Practice, vol. 26, no. 6, pp. 840-867, 2016.

[63] S. Hwang, E. Choung, J. Boo, and S.-C. Kim, "Improving Service Quality Through Managing Customer Contact: Case of Airlines," International Journal of Productivity and Quality Management, vol. 15, pp. 203-214, 2015.

[64] D. L. Kellogg and R. B. Chase, "Constructing an Empirically Derived Measure for Customer Contact," Management Science, vol. 41, no. 11, pp. 1734-1749, 1995.

[65] L. L. Price, E. J. Arnould, and P. Tierney, "Going to Extremes: Managing Service Encounters and Assessing Provider Performance," Journal of Marketing, vol. 59, no. 2, pp. 83-97, 1995.

[66] R. Daft and R. Lengel, "Information Richness. A New Approach to Managerial Behavior and Organization Design,” Research in Organizational Behavior, vol. 6, pp. 191-233, 1983.

[67] K. N. Lemon and P. C. Verhoef, "Understanding Customer Experience Throughout the Customer Journey," Journal of Marketing, vol. 80, no. 6, pp. 69-96, 2016.
[68] S. Weinzierl, M. Stierle, S. Zilker, and M. Matzner, "A Next Click Recommender System for Web-Based Service Analytics with Context-Aware LSTMs," in Proceedings of the 53rd Hawaii International Conference on System Sciences, 2020.

[69] G. Bernard, Process-Mining-based Customer Journey Analytics. PhD thesis, University of Lausanne, 2020.

[70] Q. Liang and J. Y. Chung, "Analyzing Service Usage Patterns: Methodology and Simulation," in Proceedings of the International Conference on e-Business Engineering, 2007.

[71] N. Abedzadeh, N. Nematbakhs, and M. Nematbakhs, "Using Process Mining for Customer Retention," Trends in Applied Sciences Research, vol. 5, pp. 107-119, 2010.

[72] E. Aspinall, C. Nancarrow, and M. Stone, "The Meaning and Measurement of Customer Retention," Journal of Targeting, Measurement and Analysis for Marketing, vol. 10, no. 1, pp. 79-87, 2001.

[73] R. Halvorsrud and K. Kvale, "Strengthening Customer Relationships Through Customer Journey Analysis," in Innovating for Trust, pp. 183-200, 2017.

[74] N. V. Wünderlich, F. v. Wangenheim, and M. J. Bitner, "High Tech and High Touch: A Framework for Understanding User Attitudes and Behaviors Related to Smart Interactive Services," Journal of Service Research, vol. 16, no. 1, pp. 3-20, 2013.

[75] M. Dumas, "Process Mining 2.0 - The Future of Process Mining." Virtual Presentation at the 2nd International Conference on Process Mining, 2020. 